\title{
TRADUÇÃO INTERSEMIÓTICA DE TEXTOS LITERÁRIOS: UMA ANÁLISE DA ADAPTAÇÃO CINEMATOGRÁFICA DE RAZÃO E SENSIBILIDADE
}

\author{
Fernanda Trevizan e Silva (UEM) \\ Helena Gabriela Montemezzo (UEM) \\ Josimayre Novelli Coradim (Orientadora - UEM)
}

\section{RESUMO}

A presente pesquisa visou estabelecer uma comparação entre a obra Razão $e$ Sensibilidade, escrita por Jane Austen no século XVIII e a adaptação desta para o cinema - filme de mesmo título que o livro, dirigido por Ang Lee (1995). O objeto central de estudo partiu das falas referentes à protagonista Marianne escritas por Austen em confronto com a configuração das legendas do filme adaptado. Desse modo, a análise embasou-se em autores como Marins e Wielewicki (2009), Sousa e Dias (2013) e Moura (2015), cujos trabalhos estão alocados em dois diferentes campos: o das adaptações cinematográficas e o das teorias literárias que contemplam a situação da mulher na sociedade inglesa entre as Eras Georgiana e Vitoriana. A finalidade pautou-se não só em analisar as diferenças existentes entre obra original e sua adaptação intersemiótica nos âmbitos estilísticos e textuais, como também em definir por quais fatores tais diferenças estão motivadas. Assim sendo, investigou-se determinados aspectos específicos como acréscimos, supressões e mudanças do foco narrativo. Além disso, traçou-se o perfil psicológico da personagem para verificar se o filme retrata a personalidade de Marianne de maneira semelhante ou não à criada por Jane Austen.

Palavras-chave: Tradução intersemiótica; Razão e Sensibilidade; Literatura Inglesa;

\section{INTRODUÇÃO}

Algumas das profissões desempenhadas pelas mulheres não eram vistas com bons olhos pela elite da comunidade britânica do século XVIII, sobretudo no que diz respeito à autoria de textos literários. A possibilidade de uma mulher se tornar escritora e, consequentemente, uma figura pública estava fora dos padrões aceitáveis na época. Isso se deve ao fato de que

Desde que as mulheres passaram a enunciar artisticamente seus textos de modo mais sistemático, começaram as discussões em torno de uma escrita feminina como diferença do modelo canônico masculino, como também surgiu a dificuldade de instituir a produção literária de mulheres no âmbito de uma tradição que ainda as hostilizava e colocava em xeque sua existência. Essas discussões foram enriquecidas por pensadoras que, desde o início do século XX, tentam elucidar as implicações da literatura de autoria feminina no imaginário social, por exemplo, Virginia Woolf (...) e Simone de Beauvoir (...). Elas discutiram a recusa, por parte da crítica masculina, de algumas escritoras, pela concepção, até final do século XIX, de que as obras 


\section{SEMINÁRIO DE PESQUISA EM CIÊNCIAS HUMANAS - SEPECH \\ Humanidades, Estado e desafios didático-científicos \\ Londrina, 27 a 29 de julho de 2016}

femininas são marcadas por uma feminilidade como expressão de um narcisismo/sentimentalismo exacerbado. (SOUSA; DIAS, 2013, p. 157)

Ademais, as obras de autoria feminina também carregavam consigo o peso de uma sociedade que as julgava intelectualmente inferiores àquelas produzidas pelos homens.

Inserida nesse contexto, a romancista mundialmente conhecida, Jane Austen, estava ciente das implicações de ser reconhecida publicamente. Em decorrência disso, seus primeiros livros foram publicados usando apenas o pseudônimo " $A$ Lady". As criações da autora apresentam traços marcantes de sua consciência em relação às questões financeiras as quais perpassam a vida das mulheres provincianas do final do século XVIII e início do século XIX.

Tal realidade é retratada em um dos livros de maior sucesso escrito por Austen, Razão e Sensibilidade (2012), publicado ainda em vida no ano 1811. O romance traz em seu enredo a história de duas irmãs, Elinor e Marianne Dashwood, as quais, após a morte do pai, encontram-se em situações adversas que as levam a mudar de casa, acarretando, assim, diferenças no cotidiano e em suas relações interpessoais. Tais diferenças também são evidenciadas na personalidade das irmãs - Elinor é racional enquanto Marianne se revela mais passional e emotiva -, porém esta oposição é resolvida quando ambas traçam seus caminhos rumo à felicidade desejada.

O grande sucesso, anteriormente citado, fez com que a obra ganhasse diversas adaptações. Dentre elas, uma versão na televisão com o seriado Sense and sensibility, em 1981, o qual contou com a direção de Rodney Bennett, e no cinema, com uma versão cinematográfica dirigida por Ang Lee, escrita e interpretada por Emma Thompson, cuja adaptação foi vencedora do Oscar no ano de 1996. Esta premiação rendeu sérias responsabilidades às equipes de legendagem que precisaram trazer para outras línguas a mesma excelência dos diálogos da língua original utilizada no filme.

Perante esse contexto, nosso objetivo, neste trabalho, consiste em realizar uma análise crítica das falas pertencentes à protagonista Marianne Dashwood na obra original de Austen de modo a compará-las com as apresentadas nas legendas do filme de Lee, a fim de traçar eventuais diferenças semânticas e/ou lexicais as quais podem, de alguma forma, modificar o perfil da personagem. Além disso, é também foco dessa pesquisa investigar possíveis alterações de cunho cronológico e narrativo presentes em ambas as manifestações artísticas.

\section{FUNDAMENTAÇÃO TEÓRICA}

\subsection{A literatura e o contexto social inglês entre os séculos XVIII e XIX}

É sabido que o meio histórico/social atua diretamente nas artes como um todo. Ao discutir mais especificamente a arte literária, o sociólogo, literato e professor Antonio Candido (2006) assevera que é preciso investigar as influências estabelecidas pelos fatores socioculturais, os quais apresentam-se de forma diversificada. Porém, o autor considera de maior relevância aqueles relacionados à estrutura social, aos valores e ideologias. Tais fatores marcam os quatro momentos da produção, pois "a) o artista, sob o impulso de uma necessidade interior, orienta-o segundo os padrões da sua época, 


\section{SEMINÁRIO DE PESQUISA EM CIÊNCIAS HUMANAS - SEPECH \\ Humanidades, Estado e desafios didático-científicos \\ Londrina, 27 a 29 de julho de 2016}

b) escolhe certos temas, c) usa certas formas e d) a síntese resultante age sobre o meio." (CANDIDO, 2006, p.31).

Para Candido (2006, p. 147), a literatura possui caráter de coletividade social, uma vez que "requer uma certa comunhão de meios expressivos (a palavra, a imagem), e mobiliza afinidades profundas que congregam os homens de um lugar e de um momento, para chegar a uma "comunicação". Nesse âmbito, estão inseridas questões que abrangem não só os fatos históricos da época, mas também os costumes comuns às diferentes classes. Ainda levando em conta os pressupostos de Candido (2006, p. 16), o assunto da obra "repousa sobre condições sociais que é preciso compreender e indicar, a fim de penetrar no significado".

Assim sendo, faz-se necessário realizar um estudo aprofundado sobre requisitos anteriormente mencionados - fatos históricos da época e costumes comuns às diferentes classes - a fim de analisar a construção de Marianne Dashwood, cujo perfil é influenciado de maneira direta pelos preceitos de um contexto que abrange o período de transição entre a Era Georgiana e Vitoriana, compreendendo o final do século XVIII e início do século XIX. Tal período caracteriza-se por abarcar uma sociedade patriarcal em que os interesses femininos compenetravam-se no matrimônio e seu papel se limitava à

(...) figura da dona-de-casa, da mulher santa, da mãe dedicada, diferente daquelas consideradas orgásticas, caso usassem o corpo para o prazer. As mulheres eram educadas ou incentivadas a serem frígidas, pois sentir prazer era coisa do Diabo e, portanto, passível de punição. (SOUSA; DIAS, 2013, p. 148).

Embora as condições da época retratada no romance coloquem as mulheres em uma posição inferior, Moura (2015) avalia a personagem de Austen como alguém que destoa dos padrões impostos pela sociedade inglesa em que vive, pois, ao contrário das outras, a jovem Dashwood se sente segura o bastante para expor seus sentimentos às pessoas que estão em sua volta. Essa postura é vista por Moura (2015, p. 48) como uma atitude que "não está em consonância com as emoções de seus espectadores, os outros personagens do romance, e, portanto, é considerada injusta e imprópria".

A repressão sofrida pela personagem por parte de seus espectadores está fundamentada por uma visão masculina presente nos textos canônicos, como destacam Gilbert e Gubar (1984), os quais traçam uma imagem feminina que pode ocupar um destes polos distintos e hierarquizados: ou anjos ou monstros. No que diz respeito à Marianne, seu entorno social insiste em tentar limitá-la à alegoria angelical, que (...) estaria associada à pureza, bondade, submissão, vida contemplativa, modéstia e entrega incondicional aos afazeres domésticos, aos filhos e ao marido. Em suma, o que define a mulher anjo seria a passividade. (GILBERT; GUBAR, 1984 apud SOUSA; DIAS, 2013, p.163). A partir das análises realizadas neste trabalho, compreender-se-á que a passividade não é um atributo que compõe o perfil da personagem estudada.

\subsection{A tradução intersemiótica do texto literário}

À medida que a evolução da indústria cinematográfica conquistava uma maior notoriedade, as adaptações de grandes obras do cânone literário também ganhavam seu 


\section{SEMINÁRIO DE PESQUISA EM CIÊNCIAS HUMANAS - SEPECH \\ Humanidades, Estado e desafios didático-científicos \\ Londrina, 27 a 29 de julho de 2016}

espaço. Segundo o escritor Julio Plaza (2008, p. 11), tais traduções intersemióticas consistem “(...) na interpretação dos signos verbais por meio de sistemas de signos nãoverbais"

De acordo com Marins e Wielewicki (2009, p.281), essa prática exige uma boa interpretação tanto dos recursos textuais, quanto visuais e sonoros. Logo, todo o processo de tradução intersemiótica está intrinsecamente atrelado à necessidade de ajustar os traços temporais referentes à cultura e sociedade da obra original aos moldes de seu público alvo. Dessa forma, dependendo dos objetivos almejados pelos produtores, há uma espécie de "licença" para a ocorrência de possíveis acréscimos, supressões ou alterações do texto literário.

Relacionando as questões acerca da tradução intersemiótica e a prática de legendagem, Gorovitz (2000, p. 65) destaca a complexa natureza deste processo no seguinte trecho:

Considera-se o cinema enquanto representação do homem. A partir de tal colocação, cabe afirmar que, ao descrever a realidade individual e coletiva, a imagem cinematográfica acomoda o quadro de interação entre o sujeito e a obra. Assim, a mensagem legendada, com suas ambigüidades e carências, é absorvida a partir de um processo de cooperação favorecido. Os elementos de reconhecimento asseguram o contrato apesar dos desgastes da intermediação. Ao assistir o filme, o espectador destaca na obra familiaridades e acomoda-se às estranhezas restituindo aquilo que não é explicitamente capturado.

Assim sendo, também se faz necessário pensar nas questões semânticas que somente são transmitidas ao espectador através da oralidade - "inflexões que manifestam pressupostos, subentendidos, atitudes sujeitos às variações do diálogo" (GOROVITZ, 2000, p. 66) - e que podem não ser captadas em texto escrito. Além disso, o acesso a fatores sonoros e visuais em uma adaptação cinematográfica somados às expressões faciais dos atores podem constituir mensagens que estão explícitas no texto, dispensando quaisquer outras modificações na legenda.

Desse modo, sustentamos nosso estudo nos pressupostos teóricos acima expostos com o intuito de estabelecer possíveis comparações entre as falas de Marianne Dashwood na obra original de Austen e na adaptação cinematográfica de Ang Lee, tendo suas legendas como objeto de análise para traçar o perfil da personagem em questão.

\section{ANÁLISE}

A personagem Marianne Dashwood, tanto na obra original quanto na adaptação de Ang Lee, cria pretextos variados para exacerbar sua sensibilidade excessiva. Após a perda da propriedade onde ela e a família viviam em Norland, a personagem precisa se adaptar a uma nova realidade sem recursos financeiros suficientes para viver com os mesmos luxos dos quais desfrutava anteriormente. Ao se mudar para Devonshire, a jovem Dashwood conhece várias pessoas cujos perfis se mostram diferentes dos quais estava habituada, entre elas Coronel Brandon, um elegante e experiente admirador, e John Willoughby, por quem a moça se apaixona perdidamente. 


\section{SEMINÁRIO DE PESQUISA EM CIÊNCIAS HUMANAS - SEPECH \\ Humanidades, Estado e desafios didático-científicos \\ Londrina, 27 a 29 de julho de 2016}

Entretanto, a moça acaba se desiludindo com Willoughby, pois descobre que o pretendente não correspondia à imagem antes formulada por ela. Posteriormente, devido aos fatos que se sucederam, Marianne passa a dar mais atenção para o amor e a devoção demonstrados pelo Coronel Brandon, que se dispõe a conceder seus cuidados durante a enfermidade de sua amada. A partir desse momento, a protagonista permite $o$ envolvimento sentimental com o Coronel, culminando, por fim, no casamento tão sonhado.

\subsection{Perfil psicológico da personagem Marianne Dashwood}

A finalidade desta seção é analisar os contrastes presentes entre texto literário e sua tradução intersemiótica, focalizando a personalidade de Marianne Dashwood. Para isso, essa pesquisa utilizar-se-á das legendas representadas na adaptação cinematográfica e das falas atribuídas por Austen à personagem.

Após Elinor Dashwood conhecer Edward Ferrars e demonstrar uma grande afeição por ele, Marianne e sua mãe certo dia discutem sobre suas respectivas opiniões a respeito dos predicados do rapaz. A Sra. Dashwood aprova e apoia uma possível união entre a primogênita e seu pretendente, pois, assim, a filha estaria bem amparada financeira e socialmente, uma vez que o objetivo feminino da época era um casamento bem sucedido. Entretanto, "para Marianne, o amor deve ser a junção de duas almas apaixonadas, e não um contrato selado com lucros e juros" (MOURA, 2015, p. 55). Sendo assim, ela demonstra ter medo de que o rapaz não seja bom o bastante para se casar com sua irmã.

\begin{tabular}{|l|l|}
\hline FILME & LIVRO \\
\hline "Edward é muito amável." "Mas falta & $\begin{array}{l}\text { "- Talvez - disse Marianne. - Confesso } \\
\text { que estou surpresa. Edward é muito amável }\end{array}$ \\
$\begin{array}{l}\text { Ulgo, é sério demais." "E ele saberá amar? } \\
\text { satisfazer?" "Amar é arder, estar em fogo. } \\
\text { Como Julieta, Guinevere, Heloísa." }\end{array}$ & $\begin{array}{l}\text { assim, acho que ele não é o tipo de rapaz... } \\
\text { sinto uma grande ternura por ele. Mesmo } \\
\text { aree que falta algo, ele não se sobressai } \\
\text { por sua aparência, não possui aquele } \\
\text { charme que eu esperaria de um homem pelo } \\
\text { qual minha irmã se sentisse seriamente } \\
\text { atraída. Falta-lhe mais vivacidade nos } \\
\text { olhos, aquele fogo que, ao mesmo tempo, } \\
\text { anuncia virtude e inteligência. E, além } \\
\text { disso, sinto dizer mamãe, mas ele não tem } \\
\text { bom gosto. Parece que nem a música o } \\
\text { atrai, e, embora ele admire muito os } \\
\text { desenhos de Elinor, não é a admiração de } \\
\text { uma pessoa que possa entender seu valor. } \\
\text { Está evidente que ele não sabe nada desse } \\
\text { assunto, apesar de estar sempre atento a ela } \\
\text { enquanto desenha. Ele a admira como } \\
\text { enamorado, não como profundo conhecedor }\end{array}$ \\
\hline
\end{tabular}




\section{SEMINÁRIO DE PESQUISA EM CIÊNCIAS HUMANAS - SEPECH \\ Humanidades, Estado e desafios didático-científicos \\ Londrina, 27 a 29 de julho de 2016}

\begin{tabular}{|l|l|}
\hline & do assunto. Para me sentir satisfeita, essas \\
& características devem vir juntas. Eu não \\
poderia ser feliz com um homem cujo gosto \\
não coincidisse com o meu. Ele deve \\
penetrar em todos os meus sentimentos, os \\
mesmos livros, a mesma música devem \\
encantar aos dois" (p. 17).
\end{tabular}

Tecendo um paralelo entre o filme e o romance, notamos que a personagem retratada no roteiro de Emma Thompsom se mostra de maneira mais ousada quando expõe suas convicções. Ao conversar com sua mãe, Marianne é mais incisiva e vai direto à questão da possível capacidade de o pretendente satisfazer sua irmã. Tal opinião vai de encontro com os preceitos da época, pois a satisfação feminina não era um fator determinante para a construção das uniões matrimoniais, já que a educação da mulher é que tinha por finalidade aprazer os gostos de seu cônjuge.

Privada da liberdade de usar sua voz como bem aprouvesse para evitar um grande choque social, a Marianne de Jane Austen, apesar de ainda não acreditar fielmente que Ferrars seja capaz de satisfazer Elinor, utiliza um discurso mais suavizado. Isso fica claro nas colocações feitas em referência ao rapaz "ele não se sobressai por sua aparência", "ele a admira como enamorado, não como profundo conhecedor do assunto". Além disso, ela apresenta outros argumentos para embasar suas crenças, como o fato de que não há vivacidade em seus olhos e de que ele não possui bom gosto.

Neste excerto, podemos inferir novamente o quão ousada Marianne se apresenta na adaptação de Ang Lee em comparação à personagem descrita no livro. No diálogo presente na cena abaixo, a filha da Sra. Dashwood se dirige diretamente a Edward criticando-o enquanto ele declama alguns versos de Shakespeare, ao invés de, como é narrado no romance, confessar sua frustração secretamente para a mãe.

\begin{tabular}{|l|l|}
\hline FILME & LIVRO \\
\hline "Não consegue sentir o seu desespero? & "Oh, mamãe! Como era desanimado o jeito \\
Tente outra vez!" (Dirigindo-se & $\begin{array}{l}\text { Senti muito por minha irmã. Mas ela } \\
\text { suportou tudo aquilo com tamanha } \\
\text { diretamente a Edward Ferrars) } \\
\text { compostura que parecia nem notar. Eu mal } \\
\text { me podia aguentar no lugar. Escutar } \\
\text { aqueles versos tão lindos que quase me } \\
\text { fazem perder o sentido, pronunciados com } \\
\text { aquela calma impenetrável e tamanha } \\
\text { indiferença!” (p. 17). }\end{array}$ \\
\hline
\end{tabular}

Considerando que o lançamento da adaptação cinematográfica ocorreu em 1995, consequentemente, seus produtores atribuíram uma maior liberdade à personagem original, dando-lhe ainda mais espaço na obra e criando novos diálogos os quais poderiam ser considerados impróprios pela sociedade, como já dito anteriormente. E. J. Clery (2011) assevera que as obras de Austen costumam criar um abismo comunicativo entre os personagens femininos e masculinos, justificando a modificação dos participantes nos discursos das cenas expostas acima. Ademais, tais alterações atendem 


\section{SEMINÁRIO DE PESQUISA EM CIÊNCIAS HUMANAS - SEPECH \\ Humanidades, Estado e desafios didático-científicos \\ Londrina, 27 a 29 de julho de 2016}

às expectativas do público atual sobre a liberdade de expressão feminina, levando em conta as - poucas - conquistas por parte das mulheres ao longo das décadas.

No diálogo abaixo, Sir John Middleton indaga Marianne acerca de Willoughby, rapaz por quem ela demonstra interesse. Contudo, no romance, a jovem se sente ofendida com a colocação feita pelo Sir Middleton pois, a partir dela, pode-se inferir que a moça é "atirada" pelo simples fato de exibir suas intenções sobre seu pretendente.

\begin{tabular}{|l|l|}
\hline FILME & LIVRO \\
\hline "Eu não quero nada com ninguém". & "- Ai, ai, ai... Já estou vendo tudo - disse \\
(Marianne sobre as colocações de Sir John & Sir John. - Já vejo como será. Você vai lhe \\
Middleton) & atirar a rede, e jamais pensará no pobre \\
Coronel Brandon. & - Esse é um modo de falar, Sir John, que \\
eu particularmente não gosto - disse & Marianne, calorosamente. - Eu detesto \\
frases feitas com intenções maliciosas; e \\
"atirar-lhe a rede" ou "conquistá-lo" são as \\
frases mais odiosas de todas. Essas \\
palavras têm a tendência de serem \\
grosseiras e vulgares; e se alguma vez \\
puderam ser consideradas inteligentes, há \\
muito o tempo se encarregou de destruir \\
toda sua engenhosidade" (p. 36).
\end{tabular}

Na visão da Srta. Dashwood, a afirmação exposta no trecho acima é considerada vulgar, pois reduz seus sentimentos e interesses acerca de Willoughby a uma possível relação baseada na superficialidade. Segundo Moura (2015, p. 55), tal pensamento vai de encontro com os ideais da moça, visto que, para ela, a união ideal entre um homem e uma mulher deve basear-se na reciprocidade dos sentimentos e não apenas em "um contrato selado com lucros e juros". Ademais, para Wollstonecraft (2004) apud Moura (2015), o objetivo primordial de a mulher georgiana/vitoriana não deve ser visto unicamente como uma procura incansável por um casamento estável. Assim sendo, a personagem de Austen apresenta ideais à frente de seu tempo.

Em contrapartida, no filme, a fala da personagem é reduzida apenas para " $\mathrm{Eu}$ não quero nada com ninguém", demonstrando o desejo de Marianne por encerrar o assunto. Isso ocorre pois, no contexto dos anos em que a adaptação foi produzida, não há necessidade de fazer com que a posição da moça seja transparecida a respeito da colocação de Sir. Middleton. Desse modo, considera-se que o público alvo composto por mulheres do século XX é perfeitamente capaz de inferir a ideia machista emitida por um discurso que toma os objetivos femininos como essencialmente fundamentados pela busca de um companheiro ideal.

Quando as irmãs Dashwood vão a Londres a convite de Mrs. Jennings, há uma ocasião em que acompanham sua anfitriã a um baile tradicional da metrópole, porém, as jovens sentem-se desconfortáveis diante da elite londrina presente naquele ambiente. A sensação de mal estar por parte de Marianne dá lugar a uma explosiva ansiedade no momento em que a moça avista Willoughby. 


\section{SEMINÁRIO DE PESQUISA EM CIÊNCIAS HUMANAS - SEPECH \\ Humanidades, Estado e desafios didático-científicos \\ Londrina, 27 a 29 de julho de 2016}

\begin{tabular}{|l|l|}
\hline FILME & LIVRO \\
\hline \multirow{3}{*}{ "Willoughby!” (Marianne corre em direção } & "Naquele momento, ela o viu pela primeira \\
a ele, gritando seu nome). & vez, e com rosto iluminado por uma súbita \\
& alegria, teria corrido imediatamente em sua \\
& direção se a irmã não a segurasse. \\
& - Céus! - exclamou ela - Veja! Ele está ali, \\
& bem ali! Oh! Por que ele não olha para \\
& mim? Por que não vem falar comigo?" (p. \\
& $122)$ \\
\hline
\end{tabular}

Devido ao fato de se tratar de um romance dos anos 1811, Jane Austen opta por reprimir a vontade que Marianne sente de ter "corrido imediatamente" para os braços de Willoughby, visto que essa atitude seria tida como indecorosa de acordo com as regras de convívio social feminino da época. Dessa forma, a donzela permite que Elinor a detenha. Todavia, na adaptação cinematográfica, a personagem demonstra uma atitude completamente diferente. Ao avistar o amado, a Srta. Dashwood corre em sua direção gritando "Willoughby". Com tal atitude, todos os convidados se voltam para a moça demonstrando certa reprovação. Porém, mesmo sendo censurada, a moça não se deixa abater e realiza seu desejo de, finalmente, conversar com seu pretendente. Essa conduta é mais condizente com a realidade feminina dos anos 90, em que as mulheres já se reconhecem sua autonomia para tomar iniciativas como a encenada por Kate Winslet.

\subsection{Foco narrativo, adequação de elenco, supressão e outros fatores}

Esta seção tem por finalidade realizar uma análise cujo enfoque recai sobre aspectos mais gerais os quais diferem obra literária e sua tradução intersemiótica, a saber: mudança de foco narrativo, adequação de elenco, supressão de cenas e diálogos e alteração na ordem cronológica dos contextos dialogais.

Nos excertos abaixo, Marianne expressa seus sentimentos a respeito das intenções de Mrs. Jennings de casá-la com Coronel Brandon. Ela se mostra aborrecida com a ideia de assumir qualquer compromisso com o rico pretendente por achar que ele é "velho o suficiente para ser seu pai".

\begin{tabular}{|l|l|}
\hline FILME & LIVRO \\
\hline "Que ridículo! Ela [Mrs. Jennings] não & "- Ao menos mamãe, você não pode negar \\
deixa em paz nem um idoso inválido!" & o absurdo que é essa acusação, mesmo que \\
"Ouvi-o [Coronel Brandon] reclamar de & não acredite que seja intencionalmente \\
reumatismo." (Marianne para Elinor e a & $\begin{array}{l}\text { maliciosa! Com toda certeza o Coronel } \\
\text { mãe). }\end{array}$ \\
& $\begin{array}{l}\text { Brandon é mais jovem que Mrs. Jennings, } \\
\text { porém ele é velho o suficiente para ser meu } \\
\text { pai e, se alguma vez já teve ânimo o } \\
\text { suficiente para se apaixonar, deve ter } \\
\text { sobrevivido a qualquer sensação desse tipo. } \\
\text { É muito ridículo! Quando um homem } \\
\text { poderá libertar-se de tais brincadeiras, se a } \\
\text { idade ou a doença não o protegerem? } \\
- \text { Você não o ouviu reclamando de }\end{array}$
\end{tabular}




\section{SEMINÁRIO DE PESQUISA EM CIÊNCIAS HUMANAS - SEPECH \\ Humanidades, Estado e desafios didático-científicos \\ Londrina, 27 a 29 de julho de 2016}

Ao traçar um paralelo entre a obra literária e sua tradução intersemiótica, é possível notar uma grande diferença no modo como o diálogo descrito acima é apresentado. Nas palavras de Austen, as mulheres da família Dashwood protagonizam uma longa conversa acerca desse tema, ao contrário do filme, em que isso se dá de maneira mais breve.

O roteiro escrito por Emma Thompson traz uma cena na qual, após voltar de um momento de descontração ao ar livre com suas irmãs e Mrs. Jennings - que faz insinuações ousadas sobre Marianne e Cel. Brandon -, a jovem Dashwood não hesita em demonstrar sua insatisfação em relação às ideias da senhora. Entretanto, o diálogo logo é interrompido pelo anúncio sobre a chegada do Atlas há muito prometido por Edward Ferrars. É possível, pois, inferir que a mudança de foco no enredo da adaptação foi realizada com o intuito de criar uma nova tensão na trama, uma vez que Edward garantira a Elinor que levaria o mapa pessoalmente. Essa criação de novos "conflitos" garante maior envolvimento por parte do espectador. Nesse sentido, tal prática corrobora com as ideias de Marins e Wielewicki (2009, p.281), as quais asseveram que dependendo dos objetivos almejados pelos produtores, há uma espécie de "licença" para que sejam realizados acréscimos, supressões ou alterações do texto literário.

Após Willoughby fazer uma visita à família Dashwood, Elinor repreende a atitude da irmã por demonstrar demasiado interesse pelo pretendente. Entretanto, Marianne discorda das críticas e as responde com um tom ironizado.

\begin{tabular}{|l|l|l|}
\hline FILME & LIVRO \\
\hline "Elinor: bom trabalho, Marianne, & "- Bem, Marianne - disse Elinor, assim \\
discutiram toda a poesia inglesa. Da & que ele as deixou - para uma única manhã, \\
próxima vez falarão da natureza, do amor, & acho que você se saiu muito bem. \\
não terão mais assunto e o relacionamento & Conseguiu descobrir a opinão de Mr. \\
acabará." "Marianne: acho que exagerei. & Willoughby a respeito de quase todos os \\
Deveria ter falado do tempo e das & assuntos importantes. (...) Mas como seu \\
estradas." "Elinor: ele com certeza & relacionamento com ele poderá durar um \\
percebeu seu entusiasmo." "Marianne: por & longo tempo se você esgota rapidamente \\
que deveria? Por que eu esconderia?" & todos os assuntos de conversa? Em breve \\
"Elinor: Por nenhum motivo especial, mas & todos os seus tópicos favoritos já terão se \\
o conhecemos tão pouco." "Marianne: o & esgotado. (...) \\
tempo não significa nada. Alguns nem em & - Elinor - exclamou Marianne - acha que \\
sete anos se conhecem, para outros, sete & está sendo justa? Será que tenho poucas \\
dias bastam. (...) Sinto como se já o & ideias? Porém, entendo o que disse. Fiquei \\
conhecesse." & muito à vontade, muito feliz, muito franca. \\
& $\begin{array}{l}\text { Estive em falta com toda noção comum de } \\
\text { decoro, fui aberta e sincera quando deveria } \\
\text { ter sido mais reservada, desanimada, tola e } \\
\text { hipócrita. Se tivesse falado apenas do } \\
\text { tempo e das estradas, e se tivesse aberto a } \\
\text { boca apenas uma vez a cada dez minutos, } \\
\text { teria sido poupada dessa repreensão." (p. }\end{array}$ \\
\hline
\end{tabular}




\section{SEMINÁRIO DE PESQUISA EM CIÊNCIAS HUMANAS - SEPECH \\ Humanidades, Estado e desafios didático-científicos \\ Londrina, 27 a 29 de julho de 2016}

\section{$37-38)$}

Na produção de Ang Lee, é notável que há uma pequena mudança no discurso de Marianne com relação ao romance. Essa mudança se dá por meio de um acréscimo de informações as quais não estão presentes especificamente nesse diálogo da obra original: "o tempo não significa nada. Alguns nem em sete anos se conhecem, para outros, sete dias bastam. (...) Sinto como se já o conhecesse".

Não obstante, essa informação se encontra mais adiante no livro e em um contexto diferente. Dias depois de conhecer Willoughby, o jovem intenta presentear a Srta. Dashwood com um cavalo. Quando Elinor expressa sua opinião acerca desse fato, dizendo que ainda é cedo para uma demonstração de tamanha intimidade, a moça rebate o discurso da irmã, pois acredita que já é próxima o bastante do rapaz.

- Você está enganada, Elinor - disse Marianne acaloradamente supondo que sei pouco de Willoughby. É verdade que não o conheço há muito tempo, mas conheço-o melhor que qualquer outra pessoa no mundo, com exceção de você e mamãe. Não é o tempo nem a ocasião que determinam a intimidade, mas apenas a disposição da pessoa. Sete anos não seria suficiente para algumas pessoas se conhecerem bem, ao passo que, para outros, sete dias são mais que suficientes. Sentir-me-ia culpada de uma falta maior se aceitasse um cavalo de meu irmão do que de Willoughby. Conheço John muito pouco, embora tenhamos vivido juntos durante alguns anos, mas sobre Willoughby já faz tempo que formei minha opinião (AUSTEN, 2012, p. 45).

O fragmento supracitado complementa os traços da personalidade de Marianne, uma vez que contém um argumento o qual justifica certas atitudes da personagem: "Não é o tempo nem a ocasião que determinam a intimidade, mas apenas a disposição da pessoa" (AUSTEN, 2012, p.45). Por conta disso, pode-se inferir que foi viável expor tal informação em um determinado momento do filme, ao passo que o contexto original em que ela é apresentada foi descartado pelos produtores em vista de ser dispensável para o entendimento da obra. Esse rearranjo de cenas faz com que sejam captados os aspectos essenciais para a compreensão do perfil psicológico da personagem sem que o filme se torne maçante e longo demais para seus espectadores.

Quando Mrs. Jennings convida as irmãs para acompanhá-las a Londres, Marianne fica extasiada com a possibilidade de encontrar John Willoughby novamente. A agitação da jovem é representada em ambas as obras - literária e cinematográfica -, porém, de maneiras distintas, conforme mostra o quadro abaixo:

\begin{tabular}{|l|l|}
\hline FILME & LIVRO \\
\hline "Nunca serei tão grata a alguém como a & "A alegria de Marianne estava quase acima \\
ela. Não pode estar tão calma. Nem mesmo & da felicidade, tão grande era sua agitação e \\
você! Não vou conseguir dormir. Sobre o & impaciência por partir. A única coisa que a \\
que conversou com Lucy?" (Marianne se & fazia recuperar a calma era a pouca vontade \\
dirigindo-se a Elinor). & $\begin{array}{l}\text { que tinha de deixar a mãe, e no momento da } \\
\text { partida sentiu-se bastante aflita. A tristeza } \\
\text { de sua mãe foi um pouco menor, e Elinor } \\
\text { era a única das três que parecia considerar a }\end{array}$ \\
\hline
\end{tabular}




\section{SEMINÁRIO DE PESQUISA EM CIÊNCIAS HUMANAS - SEPECH \\ Humanidades, Estado e desafios didático-científicos \\ Londrina, 27 a 29 de julho de 2016}

separação como algo que não fosse durar para sempre" (p. 111-112).

No romance de Austen, a ansiedade decorrente da viagem por parte da personagem é evidenciada pelo narrador que, a partir dos operadores de leitura apontados por Franco Junior (2009), pode ser caracterizado como heterodiegético onisciente. Essa voz narrativa, apesar não compor um personagem da história, tem ciência dos sentimentos das personagens sem que seja necessário explicitá-los através de diálogos ou monólogos. Todavia, na adaptação, os produtores julgaram razoável atribuir falas à personagem a fím de demonstrar sua "impaciência por partir" (AUSTEN, 2012, p. 111). Andar de um lado para outro, proferir suas palavras rapidamente e em um tom de voz elevado são recursos suficientes para que o espectador depreenda o entusiasmo da Srta. Dashwood.

Esse fato é visto por Eisenstein (1983, p. 213-214) como uma vantagem que o cinema dispõe para retratar conflitos psicológicos e inquietação de pensamentos, considerando a possibilidade de utilizar artifícios visuais e sonoros. Por essa razão, segundo o cineasta, o público é capaz de sentir uma maior empatia pelos sentimentos das personagens.

\section{CONSIDERAÇÕES FINAIS}

Quando o assunto é adaptação cinematográfica, muitos acreditam que essas manifestações artísticas deixam a desejar se comparadas às obras literárias originais. Em alguns casos - a exemplo de Razão e Sensibilidade (1995) -, essa concepção se mostra equivocada. Isso é evidenciado nas investigações realizadas neste trabalho, cujo objetivo pautou-se em análises críticas acerca de possíveis alterações de enredo, perfil psicológico das personagens, diálogos, foco narrativo e como tais alterações se justificam.

Assim sendo, concluiu-se que as traduções intersemióticas não tornam as obras literárias necessariamente inferiores, mas trazem uma ressignificação que as caracteriza como uma releitura a qual se adéqua a outras épocas e a diferentes interpretações.

\section{REFÊNCIAS BIBLIOGRÁFICAS}

AUSTEN, J. Razão e Sensibildiade. São Paulo: Landmark, 2012. Le Livros. PDF.

CANDIDO, A. Literatura e Sociedade. 9a ed. Rio de Janeiro: Ouro sobre Azul. 2006.

CLERY, E. J. Gender. In: COPELAND, Edward; McMASTER, Juliet. The Cambridge Companion to Jane Austen. Cambridge: Cambridge University Press, 2011

EISENSTEIN, S. M. Da literatura ao cinema: uma tragédia americana. Tradução: Vinicius Dantas. In: XAVIER, Ismail (Org). A experiência do cinema: antologia. Rio de Janeiro: Edições Graal: Embrafilme, 1983 
FRANCO JUNIOR, A. Operadores de Leitura da Narrativa. In: BONNICI, Thomas; ZOLIN, L. O. (Org.). Teoria Literária: abordagens históricas e tendências contemporâneas. Maringá: Eduem, 2009.

GILBERT, S.; SUSAN, G. The Norton anthology of literature by women: the traditions in English. 2nd edition. New York: W.W. Norton \& Company, Inc, 1996.

GOROVITZ, S. A legendagem e a participação do espectador na construção da mensagem cinematográfica. 108 p. Dissertação - UnB, Brasília. 2000.

MARINS, L. C.; WIELEWICKI, V. H. G. Pygmalion, Bernard Shaw, e sua adaptação cinematográfica: uma releitura cinquentenária do cânone literário. Literatura, História e Memória, Cascavel, vol. 5, n. 5, p. 277-289, 2009.

MOURA, F. K. A Sensibilidade de Marianne Dashwood: um olhar feminista sobre a personagem de Jane Austen. UTFPR - Curitiba, 2015.

PLAZA, J. Tradução intersemiótica. São Paulo: Perspectiva, 2008

SENSE and Sensibility. Direção de Ang Lee. Los Angeles: Columbia Pictures, 1995. $136 \mathrm{~min}$.

SOUSA, D. P. de A.; DIAS, D. L. F. Quando a Mulher Começou a Falar: literatura crítica feminista na Inglaterra e no Brasil. Gênero na Amazônia, Belém, n. 3, 2013. 